\title{
If everyone is moving forward together, then success takes care of itself*
}

T gives me great pleasure to welcome you to our new peer-review journal, Current Research: Cardiology. This Journal will serve as the official journal of the International Academy of Cardiovascular Sciences, is supported by an outstanding international Editorial Board and is published by a leading publishing house, Pulsus Group, with whom we have an excellent and enduring relationship.

Together, we are confident that this new publication will fill an existing and ever-widening gap in the world of publishing ethical peerreview journals. It will provide a window of opportunity for young researchers and investigators whose primary language is not English to have their research assessed primarily on its scientific validity and merit, and not on their lack of experience or grammatical expertise in the English language or country of origin.

Current Research: Cardiology will publish a wide spectrum of articles covering evidence-based research in both experimental and clinical aspects of cardiovascular medicine. Submission of original articles and short communications, as well as editorials and mini-reviews, will all be encouraged and welcome. Recognizing that authors have many choices for submission, our commitment is to review manuscripts expertly, fairly and provide a decision in a timely manner.

We all know the publishing world is getting smaller but more crowded and very complex. Working together ensures Current Research: Cardiology will play a significant role as a global forum for today's cardiologists. I, as Editor-in-Chief, the Editorial Board and the International Academy of Cardiovascular Sciences, have all chosen to support this promising Journal with our time, expertise and efforts. We invite you to join us in the development of this exciting and worthwhile publishing program by submitting your important research.

Prof. MUDr. Bohuslav Oštádal

*Henry Ford
Editor-in-Chief 